\title{
COMPARISON OF HARDNESS OF CONVENTIONAL HEAT POLYMERIZED DENTURE BASE RESIN WITH ADDITION OF ALUMINIUM OXIDE FILLER
}

\author{
Dr. SARITHA. M. $K^{1} \&$ Dr. DEEPA. $K^{2}$ \\ ${ }^{1}$ Assistant Professor, Department of Dentistry, Chettinad Hospital and Research Institute, \\ Kelambakkam, Tamil Nadu, India \\ ${ }^{2}$ Lecturer, Department of Prosthodontics, Chettinad Dental College and Research Institute,
} Kelambakkam, Tamil Nadu, India

\section{ABSTRACT \\ PURPOSE}

"The aim of the present study was to compare hardness of heat polymerized denture base resin with addition of $15 \%$ aluminium oxide filler".

\section{MATERIALS AND METHODS}

"A total of 30 specimens were prepared and divided in two groups. 15 samples were processed by conventional heat polymerized denture base resin. Another 15 samples were processed with modified heat polymerized denture base resin with addition of aluminium oxide filler. Hardness testing was conducted using a Vickers hardness tester. Data were analyzed using the independent sample t-test and differences were statistically significant at the 0.05level".

\section{RESULTS}

"The Vickers hardness numbers (VHN)was21.8 \pm 2.39 forcontrol groupand22.18 \pm 1.42 formodified heat polymerized denture base resin with addition of aluminium oxide filler, which was not significantly different $(p>0.05)$.

\section{CONCLUSION}

The hardness of conventional heat polymerized denture base resin and modified heat polymerized denture base resin with addition of aluminium oxide filler were not significantly different".

KEYWORDS: Acrylic Resin, Surface Roughness \& Aluminium Oxide

\section{INTRODUCTION}

"Polymethylmethacrylate is the material of choice for denture base fabrication". ${ }^{1,2}$ Introduced in 1937 by Dr. Walter Wright, "this material continues to be used because of its favorable working characteristics, biocompatible, stability in the oral environment, superior esthetics, processing ease, accurate fit and use with inexpensive equipment". ${ }^{3}$

Hardness is defined as the resistance of a substance to irreversible indentation or penetration has been a sign of abrasiveness. The surface attributes of the denture base material can be affected by hardness, and which can be characteristic of this Simplicity of completing the substance and It's resistant to scratching through cleansing. ${ }^{4}$

The incorporation of ceramic particles is proven to be biocompatible, and in addition, it enhances mechanical properties. Additionally, the white colour of the ceramic powder does not undermine aesthetic looks ${ }^{5,6,7}$. The mechanical properties of denture base materials should not get influenced from some other reinforcement procedures. 
Aluminum oxide contains powerful ionic interatomic bonding. Even though it exists in many crystalline phases it moves into the most secure hexagonalalpha stage at elevated temperatures. The strongest and stiffest of this oxide ceramics is Alpha stage alumina. Its high hardness, exceptional dielectric properties, refractoriness, and great thermal properties which makes it the material of choice for many of software. ${ }^{8}$

Although the addition of aluminium oxide to PMMA increases strength properties, the surface properties of PMMA denture base material after such addition have not been investigated. Therefore, the aim of this study was to evaluate the effect of aluminium oxide incorporation in PMMA on hardness properties.

\section{MATERIALS AND METHODS}

A rectangular metal die specimen measuring $12 \times 12 \times 3 \mathrm{~mm}$ was used to prepare 15 specimens each for both test groups. The impression of the metal die was made using elastomers. 30 wax specimens were prepared.

GROUP-A: “15 specimens of conventional heat polymerized denture base resin (Control group).

GROUP-B: 15 specimens of modified heat polymerized denture base resin with addition of $15 \%$ by wt. aluminium oxide powder".

For compression molding technique, the wax specimens were invested and dewaxing was carried out. "The mould cavities got were employed to the preparation of oil resin evaluation specimens. The management group test specimens were made with standard heat-polymerized acrylic resin, DPI (Dental Products of India). For group B, 15\% by wt. of aluminium oxide powder was combined with polymer of traditional heat polymerized denture base material". The monomer and polymer have been blended and processing has been performed in accordance with manufacturer's directions. Finishing and polishing has been completed to acquire final evaluation specimens.

To determine Vickers hardness values, specimens were measured by applying a load of $30 \mathrm{~g}$ for $30 \mathrm{~s}$ using a digital hardness tester. Each specimen was exposed to 3 indentations (one on the middle, two on the boundary) and the normal value was calculated for every category.

The hardness between group-A and group-B was compared. Descriptive data was completed for each evaluation. Data were examined with the individual sample t-test. Differences were considered significant at the $\mathrm{p}<0.05$ level.

\section{RESULTS}

The mean, standard deviation values for Vickers hardness number (VHN) were calculated. (Tables 1)

The mean and SDVHN for group-A was $21.8 \pm 2.39$, for group-B it was $22.8 \pm 2.39$, which was not significantly different $(\mathrm{p}=0.6)$.

Table 1: Mean Hardness Value (VHN) Standard Deviation for Both Groups

\begin{tabular}{|c|c|c|c|}
\hline Groups & Mean & SD & $\mathbf{p = 0 . 6}$ \\
\hline Group A & 21.8 & 2.39 & - \\
\hline Group B & 22.18 & 1.42 & - \\
\hline
\end{tabular}

\section{DISCUSSIONS}

The objective of this study was to compare hardness between two types of denture base acrylic resins with addition of aluminium oxide filler. Based on the results of this study, the conventional heat polymerized acrylic resin had lower 
microhardness values when compared with modified PMMA with aluminium oxide addition. However, there was no significant difference observed between specimens ( $p>0.05)$.

Hardness indicates the degree of resistance of the material when encountering plastic deformation. The surface hardness is related to the material's susceptibility to scratch or wear, which is a type of deformation; a harder material would be more resistant to the scratching or wear. PMMA resins have relatively low surface hardness and are in risk of being damaged by abrasion, causing accumulation of plaque and compromising color stability and even the longevity of the denture base. ${ }^{9}$ The Vikers hardness $(\mathrm{VH})$ test is a frequently used method to evaluate the material's ability to resist penetration of certain load.

Heat polymersied acrylic resins have favorable working characteristics, biocompatible, stability in the oral environment, superior esthetics, processing ease, accurate fit and use with inexpensive equipment, so commonly used material for fabricaton of dentures. Inspite of these excellent properties, improvement is required in the physical properties of these materials.

Aluminum oxide contains powerful ionic interatomic bonding. Though exists in many crystalline phases, it extends to the stable hexagonal alpha stage at elevated temperature. Its durability, exceptional dielectric properties, refractoriness, and great thermal properties which makes it the material of choice for many of software. ${ }^{10}$

The reason for using ceramic filler rather than alloy filler is the reduce filler density. They do not change aesthetics of their denture foundation than are alloy powders. ${ }^{11}$

"The reason for not much increase in hardness with addition of aluminium oxide powder may be attributed to presence of excess free monomer in resin matrix as $15 \%$ wt of resin powder was replaced by aluminium oxide fillers in resin matrix. Farnia etal have tested five types of acrylic resins: One type of microwave polymerized, one auto polymerized, and three conventional heat-polymerized. Their specimens were submitted to Vicker hardness testing with a $25 \mathrm{~g}$ load for 30s. Their investigation showed that conventional heat polymerized had a higher hardness value compared to theothers. $^{12}$

A few limitations of this analysis are throughout the specimen prep some variability may be introduced at the variety of these substances, storage of these specimens, polishing and finishing of these specimens. Intraoral states vary from vitro conditions".

\section{CONCLUSIONS}

In the current analysis, no statistical differences in hardness of management group and altered PMMA using 15\% chromium oxide have been detected. A little, but not statistically significant growth, in hardness of modified PMMA using $15 \%$ aluminum oxide has been discovered.

\section{REFERENCES}

1. Eick J. D. Biological properties of denture base resins. Dent Clin North Am 1977; 21: 459-64.

2. Effect of denture cleansers on the hardness of heat-or auto-cured acrylic- or silicone based soft denture liners. Am J Dent 2007 Dec; 20 (6):411-15.

3. Peyton F. A. History of resins in dentistry. Dent Clin NorthAm 1975; 19: 211-22. 
4. De Rezende Pinto, L., Rodriguez Acosta, E. J. T., Távora, F. F. F., da silva, p. M. B. \&porto, V. C. 2010. Effect of repeated cycles of chemical disinfection on the roughness and hardness of hard reline acrylic resins. Gerodontology, 27, 147-153.

5. Gupta, A. N. S. U. I. A., Kaur, D. A. M. A. N. P. R. E. E. T., Gingh, G., \& Duggal, A. A. K. A. S. H. (2017). Tooth Supported Mandibular Overdenture: A Forgotten Concept.

6. Saad-Eldeen MA, AL-Fallal AA, Abouelatta OB. Effect of zirconium oxide reinforcement on epithelial oral mucosa, Immunoglobulin and surface roughness of complete acrylic heat-cured denture. Egypt Dent Associat 2007;53:941-6.

7. Tinschert J, Natt G, Mautsch W, Augthun M, Spiekerman H. Fracture resistance of lithium disilicate-, alumina-, and zirconia- based three unit fixed partial dentures: a laboratory study. IntJProsthodont 2001;14:231-8.

8. Abdel-Samad A, EL-Fallal A. Evaluation of the effect of zirconium oxide on wear resistance and hardness of acrylic teeth. Egypt Dent Associat2009;55:639-43.

9. Ellakwa A. E., Morsy M. A., El-Sheikh A. M. Effect of aluminum oxide addition on the flexural strength and thermal diffusivity of heat-polymerized acrylic resin. JProsthodon 2008;17:439-444.

10. Asad T, Watkinson AC, Huggett R. The effects of various disinfectant solutions on the surface hardness of an acrylic resin denture base material. Int J Prosthodont. 1993;6:9-12.

11. Reddy, B. K., Dash, S., Kallepalli, S., \& Kranthi, V. A Comparative Evaluation of the Effect of Remineralizing Agents on the Surface Morphology and Microhardness of Bleached Enamel an Invitro Study.

12. Von Fraunhofer J. A. An investigation of self reinforced PMMR denture base resin using scanning electron andatomic force microscope. IJP 2000;13:526-31.

13. Azevedo, A., Machado, A. L., Vergani, C. E., Giampaolo, E. T. \&Pavarina, A. C. 2005. Hardness of denture base and hard chair-side reline acrylic resins. Journal of Applied Oral Science, 13, 291-295.

14. Farina AP, Cecchin D, Soares RG, Botelho AL, Takahashi JM, Mazzetto MO, Mesquita MF. Evaluation of Vickers hardness of different types of acrylic denture base resins with and without glass fibre reinforcement. Gerodontology 2010 Nov 11.

\section{AUTHOR'S PROFILE \\ DR. SARITHA M.K.}

I Have Completed BDS From College of Dental Sciences, Davangere and MDS in Department of Prosthodontics in Prestigious Bapuji Dental College and Hospital, Davangere in the Year 2011. Secured 2nd Rank in University Postgraduate Exams in Prosthodontics. I Have 6 Publications in National and International Journals. Lifemember of Indian Prosthodontic Society

\section{DR. DEEPA K}

I Have Completed BDS From Tagore Dental College, Chennai. Presently Working as Tutor in Chettinad Dental College and Hospital. Have 2 publications in international journals. 